\title{
Immune parameters, symptoms of upper respiratory tract infections, and training-load indicators in volleyball athletes
}

This article was published in the following Dove Press journal:

International Journal of General Medicine

I3 December 201।

Number of times this article has been viewed

\section{Rodrigo Dias' \\ Anelena Bueno Frollini' \\ Diego Trevisan Brunelli ${ }^{\prime}$ \\ André Katayama Yamada' \\ Richard Diego Leite ${ }^{4}$ \\ Ricardo Adamoli Simões' \\ Guilherme Souza Lobo Salles' \\ Débora Trevisan' \\ Idico Luiz Pellegrinotti' \\ Marcelo de Castro César ${ }^{1}$ \\ Silvia Cristina Crepaldi Alves' \\ Rozangela Verlengia' \\ João Paulo Borin ${ }^{2}$ \\ Jonato Prestes ${ }^{2,3}$ \\ Claudia Regina Cavaglieri \\ 'Núcleo de Performance Humana, Mestrado em Educação Física, \\ Faculdade de Ciências da Saúde, Universidade Metodista de Piracicaba, \\ São Paulo, Brasil; ${ }^{2}$ Faculdade de \\ Educação Física (FEF) Universidade \\ Estadual de Campinas - UNICAMP, \\ Campinas, Brasil; ${ }^{3}$ Programa de \\ Mestrado e Doutorado em Educação \\ Física, Universidade Católica de \\ Brasília, Brasília, Brasil; ${ }^{4}$ Laboratório \\ de Pesquisa Clínica e Experimental \\ em Biologia Vascular (BioVasc), \\ Departamento de Ciências Fisiológicas, \\ Universidade Estadual do Rio de Janeiro, \\ Rio de Janeiro, Rio de Janeiro, Brasil}

Correspondence: Cláudia Regina Cavaglieri Faculdade de Educação Física,

Universidade Estadual de

Campinas - UNICAMP Av. Érico

Veríssimo, 70I - Campinas, São Paulo,

Brasil CEP: | 3083-85 |

Tel +55 I9 352। 6625

Fax +551935217493

Email cavaglieri@fef.unicamp.br
Background: The control of immunological alterations becomes important during in-season training, as a result of increased incidence of infectious diseases, and may assist in avoiding interruptions to training due to illness.

Objective: The aim of the present study was to evaluate 28 weeks of chronic immune modulations in female volleyball athletes.

Methods: The sample was composed of twelve athletes aged $19.47 \pm 2.49$ years, height $1.78 \pm 0.08 \mathrm{~cm}$, and body mass $66.77 \pm 7.8 \mathrm{~kg}$. Leukocytes, individual immune cell count, interleukin (IL)-2, IL-6, and tumor necrosis factor (TNF)- $\alpha$ plasma cytokines were measured during the competitive period.

Results: Results revealed that immune variables were correlated with symptoms of upper respiratory tract infections and training-load indicators, indicating a possible marker of immune status. There was a statistically significant increase in total leukocytes, neutrophils, and monocyte count, a decrease in lymphocytes, and an increase in upper respiratory tract infection symptoms, with no change in IL-2, IL-6, and TNF- $\alpha$. Correlations between subjective levels of tiredness, total leukocyte count, and neutrophils with upper respiratory tract infection symptoms were observed.

Conclusion: In conclusion, these correlations can represent important tools to access the immune status of an athlete during long training periods, preventing a possible immunosuppressive status.

Keywords: immune system, leukocytes, cytokines

\section{Introduction}

During in-season training and after major competitions, the incidence of upper respiratory illness (URI) in athletes, such as cold, sore throat, and others, is increased. The higher incidence of URI in athletes may be associated with exercise-induced changes in stress hormones, such as catecholamine, adrenocorticotropic hormone, and cortisol, ${ }^{1-3}$ body temperature changes, dehydration, exercise-induced changes in cellular glutamine metabolism, and lymphocyte apoptosis. ${ }^{2-5}$ These modifications result in a decreased organic defense, including lower lymphocyte functionality, proliferation, count, and antibody production, higher neutrophil count, and elevated plasma pro-inflammatory cytokine levels. ${ }^{6-11}$

Nieman et $\mathrm{al}^{12}$ demonstrated a higher incidence of URI in endurance athletes after a major competition or during periods of intense training. Some studies have demonstrated a higher incidence of URI in endurance marathon and ultramarathon runners. ${ }^{13,14}$ The interactions between exercise, the immune system, and susceptibility to URI have 
been studied inside the sport context, mainly in endurance exercise..$^{8-11,14,15}$ However, there are few studies analyzing the immune response in team sports with intermittent action, such as volleyball, basketball, and handball, during training and competitive periods. ${ }^{16-18}$

Córdova et $\mathrm{al}^{1}$ studied the chronic effects of training and competition during a 4-month season on the immune response of professional volleyball players. The study showed higher immunoglobulin concentration and lymphocyte count after a seasonal training period. In contrast, another study showed no significant changes in interleukin (IL)-6 and tumor necrosis factor (TNF)- $\alpha$ in volleyball athletes during 1 month of increasing training load. ${ }^{19}$

The high training intensity can promote a greater release of stress-associated hormones, such as catecholamines and cortisol, which modulate the immune system. ${ }^{10,15}$ In addition, there is a correlation between pro-inflammatory cytokines (IL-1 $\beta$, IL-6, and TNF- $\alpha$ ) with the activation of the hypothalamic-pituitary-adrenal axis and the inhibition of the hypothalamic-pituitary-gonadal axis. ${ }^{20}$ This highlights the correlation between cytokines and neuroimmunoendocrine and metabolic modulation. Higher serum pro-inflammatory cytokine levels, mainly IL-6 and TNF- $\alpha$, have been observed after marathon running ${ }^{9,10,15}$ and have been correlated with increased incidences of URI as a result of excessive training loads and competition. In this sense, high levels of pro-inflammatory cytokines can represent a catabolic milieu inducing a higher incidence of URI. ${ }^{8}$

The control of immunological alterations becomes important during in-season training, as a result of the increased incidence of infectious diseases, and may assist in avoiding interruptions in training due to illness. Thus, the magnitude and duration of immunological changes during a season of training for volleyball needs to be clarified.

In view of the abovementioned concerns, the present study aimed to evaluate chronic immune modulations in female volleyball athletes undergoing a competitive period, by the analysis of total and individual leukocyte count, and IL-2, IL-6, and TNF- $\alpha$ plasma levels. Additionally, these variables were correlated with URI symptoms and trainingload indicators.

\section{Methods \\ Subjects}

Professional female players $(n=12)$ from the Piracicabana Association of Volleyball, affiliated to the Paulista Federation of Volleyball; participated during the regular season of competition in the Paulista league (age 19.47 \pm 2.49 years; height $1.78 \pm 0.08 \mathrm{~m}$, body mass $66.77 \pm 7.8 \mathrm{~kg}$, body fat percentage $18.96 \% \pm 2.86 \%$, lean body mass $53.98 \pm 5.38 \mathrm{~kg}$, and fat mass $12.78 \pm 2.99 \mathrm{~kg}$ ). Body fat percentage was estimated according to the equation of Jackson et al. ${ }^{21}$ Volunteers were informed of all the risks before the investigation and signed an informed consent document. The present research was approved by the Research Ethics Committee of the Methodist University of Piracicaba (protocol no. 02/06) and is in accordance with the legal requirements of the Declaration of Helsinki.

\section{Competitive period}

Training periodization was composed of four periods: preparatory ( 7 weeks); pre-competitive ( 5 weeks); competitive I ( 8 weeks), and competitive II (20 weeks). Individuals performed two 3-hour training sessions per day (morning and night), 5 days per week. The main differences between these training periods are associated with load content applied in each period, whereas competitive exercises present in the competitive periods exert an important effect on tiredness, resulting from a higher intensity of muscle action in this type of exercise as compared with general and special exercises. Additionally, competitive exercises produce a higher psychological stress in athletes (Table 1). ${ }^{22}$

The timing of the evaluations was as follows. Diagnostic evaluations included: anthropometry and immune variables in May (ending of the pre-competitive period and initiation of the competitive I period; fall season, M1). Summative evaluations included: immune variables in July (ending of the competitive I period and initiation of competitive II; winter season, M2) and December (end of the competitive II period; end of spring season, M3). Formative evaluations included: training loads and tiredness subjective scale

Table I The percentage distribution of exercise types performed during periodization

\begin{tabular}{|c|c|c|c|}
\hline & MI & M2 & M3 \\
\hline \multicolumn{4}{|c|}{ Type of exercises } \\
\hline General & 53.45 & 46.31 & 47.08 \\
\hline Special & 35.99 & 40.12 & 34.42 \\
\hline Competitive & 10.56 & 13.57 & 18.5 \\
\hline \multicolumn{4}{|l|}{ Components } \\
\hline Physical & 43.82 & 35.17 & 41.06 \\
\hline Technical & 19.31 & 17.48 & 16.70 \\
\hline Competitive & 36.87 & 47.34 & 42.24 \\
\hline
\end{tabular}

Abbreviations: MI, pre-competitive period; $\mathrm{M} 2$, competitive I period; $\mathrm{M} 3$, competitive Il period. 


\section{Experimental design}

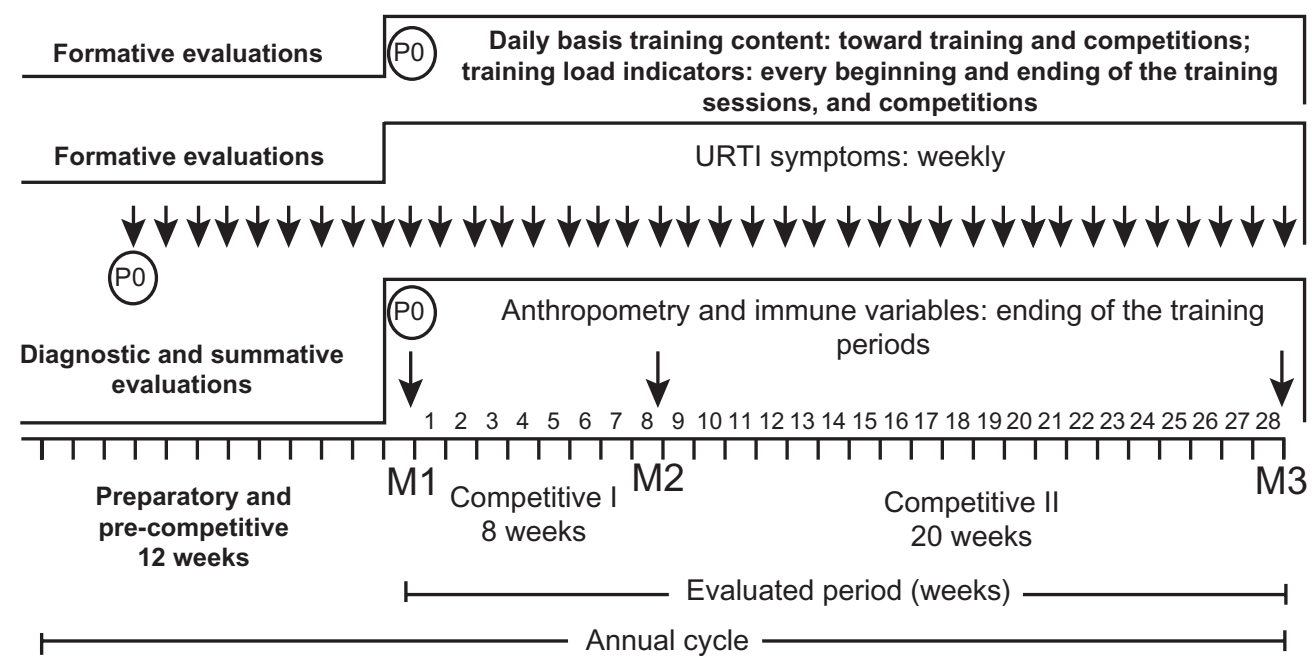

Figure I Evaluations toward training periods and competitions.

Abbreviation: URTI, upper respiratory tract infection.

toward training sessions and competitions; weekly incidence of infection episodes. Data collection (P0) is shown in Figure 1.

\section{Analysis of training load indicators}

Subjective perception of tiredness (SPT) was defined by the rating of perceived exertion of each athlete before and after sessions or games as based on the effort scale by Borg, ${ }^{23}$ adapted for tiredness. After each training session the duration in minutes was recorded and was defined as the training volume. In addition to this procedure, the scale of subjective perception of intensity proposed by Foster ${ }^{22}$ was presented to the athletes to calculate the load of each session. The participant was addressed the following question: "What was the intensity of the training in regard to the scale?" The daily training load is defined as the relationship between effort quality (intensity) and volume of training. Thus, training-load indicators were obtained according to Foster. ${ }^{22}$
Daily load $(\mathrm{DL})=$ SPT $\times$ daily session training duration in minutes; mean weekly load (MWL), sum of DL, and total weekly load $(\mathrm{TWL}=$ sum of $\mathrm{DL} /$ number of training days) were determined in arbitrary units ${ }^{22}$ (Table 2). SPT was evaluated initially (SPTI) and at the end (SPTF) of court sessions. $^{23}$

\section{Symptoms of URI}

The incidence of URI symptoms was recorded weekly during the entire period of the study. At the beginning of each training week, athletes were asked about the incidence of URI symptoms. After that, the number of symptoms was recorded. The URIs were defined by symptoms of runny nose, cold, otitis, headache, sore throat, fever, and other symptoms for at least two consecutive days as described by Tsai et al. ${ }^{24}$ The evaluation of URI symptoms was performed weekly due to the difference between competitive periods and training weeks.

Table 2 Training variables monitored during the competitive periods

\begin{tabular}{|c|c|c|c|}
\hline & MI & M2 & M3 \\
\hline TL & $7845.37 \pm 238.16$ & $5567.75 \pm 175$ & II $568.78 \pm 425.17^{\mathrm{a}, \mathrm{b}}$ \\
\hline MWL & $474.34 \pm 19.89$ & $466.26 \pm 24.77$ & $410.40 \pm 10.76^{\mathrm{a}, \mathrm{b}}$ \\
\hline TWL & $19456.13 \pm 7|5.2|$ & $16393.08 \pm 641.44$ & $33023.67 \pm 1555.95^{\mathrm{a}, \mathrm{b}}$ \\
\hline SPTI & $10.41 \pm 0.11$ & $11.02 \pm 0.22$ & $11.36 \pm 0.14$ \\
\hline SPTF & $12.06 \pm 0.21$ & $12.26 \pm 0.24$ & $12.95 \pm 0.24$ \\
\hline
\end{tabular}

Notes: Values are presented as mean \pm standard deviation; ${ }^{\mathrm{M}} \mathrm{M} 2$ and $\mathrm{M} 3$ are significantly different from $\mathrm{MI}$; ${ }^{\mathrm{b}} \mathrm{M} 3$ significantly different from $\mathrm{M} 2$; $P \leq 0.05$.

Abbreviations: TL, total load; MWL, mean weekly load; TWL, total weekly load; SPTI, subjective perception of tiredness evaluated before court sessions; SPTF, subjective perception of tiredness evaluated at the end of court sessions; MI, pre-competitive period; M2, competitive I period; M3, competitive II period. 


\section{Analysis of immune cells and cytokines}

Blood draws were performed at rest ( 24 hours after the last training session), and 8 hours fasting; between 8 am and 9 am in the morning. Immediately after the draw, hematocrit and total and individual leukocytes count were measured, and plasma was stored at $-70^{\circ} \mathrm{C}$ for cytokine determination. A capillary tube was filled to approximately $75 \%$ capacity and centrifuged for 5 minutes, while a reading card was used for hematocrit determination; results were expressed by the relative number of cells (\%).

The count of total leukocytes was accomplished with $10 \mu \mathrm{L}$ of blood by adding $190 \mu \mathrm{L}$ of Turkey liquid (Sigma, St Louis, MO) in an eppendorf, homogenized, and the count was performed in a Neubauer chamber. The circulating levels of neutrophils, lymphocytes, monocytes, eosinophils, and basophils were measured under an optical microscope using a blood smear stained with Giemsa-May Grünwald (Sigma). The analyses were performed on an optical microscope. Results were expressed as number of cells per $\mathrm{mm}^{3}$.

Measurements of IL-2, IL-6, and TNF- $\alpha$ in plasma were made by Enzyme-linked immunosorbent assay using the R\&D Systems Quantitative High Sensitivity kit (R\&D Systems, Minneapolis, MN) for each cytokine in duplicate. The intra-assay coefficient of variance (CV) was 3.2\%-10.0\%, the inter-assay CV was $4.5 \%-9.0 \%$, and the sensitivity was $0.0083 \mathrm{pg} / \mathrm{mL}$. Minimal levels detected for IL-2, IL-6, and TNF- $\alpha$ were $10.13,1.09$, and $4.57 \mathrm{pg} / \mathrm{mL}$, respectively.

\section{Statistical analyses}

The statistical analysis was initially evaluated by the ShapiroWilk normality test and by the homoscedasticity test (Bartlett criterion). Since all variables presented a normal distribution and homoscedasticity, a repeated-measures analysis of variance was used, and when the difference was significant, the Tukey post-hoc test for multiple comparisons was applied. Pearson's correlation test was used to determine possible correlations between the analyzed variables. In all calculations, a critical level of $P \leq 0.05$ was fixed. Results were expressed by mean \pm standard error of the mean. The software package used was Statistica (v 6.1; Stat Soft Inc, Tulsa, OK).

\section{Results}

\section{Training variables}

There was a statistically significant difference in trainingload variables between the different training phases. Total load and total weekly load were higher in M3 as compared with M1 and M2 $(P<0.05)$. Conversely, mean weekly load was lower in M3 as compared with M1 and M3 $(P<0.05)$
(Table 2). However, there was no statistically significant difference in SPTI and SPTF between training periods.

\section{Blood analysis}

There was no statistically significant alteration in hematocrit. Results revealed a significant increase in total leukocytes in the M2 $(P<0.01)$ and M3 $(P<0.01)$ competitive periods compared with M1. Lobulated neutrophils were significantly higher in M2 $(P<0.001)$ and M3 $(P<0.05)$ as compared with M1. The same results were observed for total neutrophils, monocytes, and neutrophils/lymphocytes $(P<0.05)$ (Table 3$)$.

In contrast, there was a significant decrease in total lymphocyte count in M3 when compared with M1 $(P<0.05)$ and M2 $(P<0.001)$. Basophils, eosinophils, and hematocrit presented no statistically significant difference when compared at all training periods. The measures of IL-2, IL-6, and TNF- $\alpha$ did not change (Table 3 ).

\section{Symptoms of URI}

Symptoms of upper respiratory tract infections increased as the training season progressed. There was a higher incidence of symptoms in $\mathrm{M} 2(P<0.001)$ and $\mathrm{M} 3(P<0.01)$ as compared with M1. There was a higher incidence of runny nose and cold during the training season $(P<0.05$; Table 4$)$.

On the other hand, sore throat was significantly higher in M2 and M3 compared with M1. Moreover, there was a lower incidence of sore throat symptoms in M2 compared with M3, although this difference was not statistically significant. There was no difference in fever and other symptoms between the training periods (Table 4). There was a positive correlation between total leukocytes and training load parameters (0.73) in M2. Similarly, neutrophil count presented a significant correlation with TWL (0.71) and SPTF $(0.67)$ in M2. Moreover, there was a negative correlation between lymphocytes and MWL in the M2 training period $(-0.62)$ (Table 5). At the end of the M3 training period, there was a positive correlation between IL-6 levels and SPTF (0.71) (Table 5).

Symptoms of upper respiratory tract infections also presented correlations with training load. There was a positive correlation between total symptoms and TWL (0.78), SPTI (0.80), and SPTF (0.90) in M2 and M3 training periods. Runny nose was positively correlated with TWL (0.60), SPTI (0.63), and SPTF (0.79) at the end of the M2 training period, and SPTF (0.74) at the end of M3 (Table 6).

The same positive correlation was observed for cold symptoms and TWL (0.60), SPTI (0.65), SPTF (0.79) in M2. However, at the end of the M3 training period, 
Table 3 Hematocrit, total and individual leukocytes count, and plasma cytokine levels during periods of evaluation in volleyball athletes $(\mathrm{n}=12)$

\begin{tabular}{|c|c|c|c|}
\hline Blood variables & MI & M2 & M3 \\
\hline Hematocrit, \% & $38.58 \pm 0.64$ & $39.67 \pm 0.75$ & $38.89 \pm 1.040$ \\
\hline Total leukocytes, cells $/ \mathrm{mm}^{3}$ & $11616.67 \pm 433.77$ & $13650.00 \pm 150.0^{\mathrm{a}}$ & $|3666.67 \pm 578.3|^{a}$ \\
\hline Neutrophils lobulated, cells $/ \mathrm{mm}^{3}$ & $906.17 \pm 137.59$ & $1 \mid 148.50 \pm 112.26$ & $1644.22 \pm 78.84^{\mathrm{a}, \mathrm{b}}$ \\
\hline Neutrophils segmented, cells $/ \mathrm{mm}^{3}$ & $4805.25 \pm 334.97$ & $5384.33 \pm 317.81$ & $6712.11 \pm 466.18^{\mathrm{a}}$ \\
\hline Total neutrophils, cells $/ \mathrm{mm}^{3}$ & $57 \mid 1.42 \pm 413.18$ & $6532.83 \pm 388.03$ & $8356.33 \pm 421.55^{\mathrm{a}, \mathrm{b}}$ \\
\hline Monocytes, cells $/ \mathrm{mm}^{3}$ & $549.25 \pm 48.72$ & $968.17 \pm 71.24^{\mathrm{a}}$ & $1181.22 \pm 102.40^{\mathrm{a}}$ \\
\hline Basophils, cells $/ \mathrm{mm}^{3}$ & $16.00 \pm 12.20$ & $17.17 \pm 8.97$ & $47.44 \pm 16.24$ \\
\hline Eosinophils, cells $/ \mathrm{mm}^{3}$ & $30.25 \pm 9.22$ & $74.25 \pm 15.96^{\mathrm{a}}$ & $36.67 \pm 11.69$ \\
\hline Total lymphocytes, cells $/ \mathrm{mm}^{3}$ & $5309.75 \pm 306.35$ & $6057.58 \pm 322.76$ & $4045.00 \pm 198.42^{\mathrm{a}, \mathrm{b}}$ \\
\hline Neutrophils/lymphocytes, cells $/ \mathrm{mm}^{3}$ & $1.14 \pm 0.14$ & $1.16 \pm 0.15$ & $2.10 \pm 0.14^{\mathrm{a}, \mathrm{b}}$ \\
\hline $\mathrm{IL}-2, \mathrm{pg} / \mathrm{mL}$ & $1.67 \pm 0.39$ & $1.71 \pm 0.45$ & $1.65 \pm 0.37$ \\
\hline $\mathrm{IL}-6, \mathrm{pg} / \mathrm{mL}$ & $1.78 \pm 0.25$ & $2.04 \pm 0.13$ & $2.30 \pm 0.15$ \\
\hline TNF- $\alpha, p g / m L$ & $1.13 \pm 0.62$ & $1.04 \pm 0.30$ & $1.03 \pm 0.27$ \\
\hline
\end{tabular}

Notes: Values are presented as mean \pm standard error of the mean; ${ }^{\mathrm{M}} \mathrm{M} 2$ and $\mathrm{M} 3$ significantly different from $\mathrm{MI}$; ${ }^{\mathrm{b}} \mathrm{M} 3$ significantly different from $\mathrm{M} 2 ; \mathrm{P} \leq 0.05$. Abbreviations: IL, interleukin; TNF, tumor necrosis factor; MI, pre-competitive period; M2, competitive I period; M3, competitive II period.

there was a positive correlation between cold, SPTI (0.78), and SPTF (0.85). Sore throat also presented a significant correlation with TWL (0.74), SPTI (0.67), and SPTF (0.74) in M2 (Table 6).

\section{Discussion}

The purpose of the present study was to evaluate chronic modulations on immune variables in female volleyball athletes, undergoing a competitive period. Another objective was to investigate the correlation between URI symptoms and training-load indicators. Results revealed a higher incidence of symptoms of upper respiratory tract infections in both competitive periods. Moreover, there was an increase in the leukocyte count and IL-2, while no modification in IL-6 and TNF- $\alpha$ was observed.

The results from this study suggest that some aspects of the immune function are modulated by training intensity and volume, which may have implications on URI incidence in

Table 4 Symptoms of URTI during the periods of evaluation in volleyball athletes $(n=12)$

\begin{tabular}{llll}
\hline URTI symptoms & MI & M2 & M3 \\
\hline Runny nose & $0.04 \pm 0.02$ & $0.21 \pm 0.05^{\mathrm{a}}$ & $0.21 \pm 0.03^{\mathrm{a}}$ \\
Cold & $0.02 \pm 0.01$ & $0.15 \pm 0.04^{\mathrm{a}}$ & $0.19 \pm 0.03^{\mathrm{a}}$ \\
Sore throat & $0.03 \pm 0.02$ & $0.27 \pm 0.07^{\mathrm{a}}$ & $0.16 \pm 0.03^{\mathrm{a}}$ \\
Fever & $0.01 \pm 0.01$ & $0.07 \pm 0.04$ & $0.03 \pm 0.02$ \\
Others & $0.00 \pm 0.00$ & $0.01 \pm 0.01$ & $0.00 \pm 0.00$ \\
Total symptoms & $0.10 \pm 0.04$ & $0.74 \pm 0.15^{\mathrm{a}}$ & $0.60 \pm 0.08^{\mathrm{a}}$ \\
\hline
\end{tabular}

Notes: Values are presented as mean \pm standard error of the mean; ${ }^{\mathrm{M}} \mathrm{M} 2$ and $\mathrm{M} 3$ significantly different from $M I ; P \leq 0.05$.

Abbreviations: MI, pre-competitive period; $M 2$, competitive I period; $M 3$, competitive II period; URTI, upper respiratory tract infection. athletes. Moreover, the total number of symptoms increased from the M1 to M2 training periods. Thus, illness during a competitive period can represent a suppression of some immune variables, increasing the risk of URI. ${ }^{25}$ This result can be associated with a higher training volume, as well as higher training intensity. These results were not observed when M2 and M3 were compared. Regarding modulation of the immune system by exercise, few studies have demonstrated the responses in team sports during a season of training. ${ }^{1,16-18}$

Immune modulations, such as elevation of neutrophils and decrease in lymphocytes have been found in

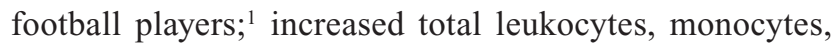
and neutrophils, with no modification in eosinophils and lymphocytes have been found in soccer players ${ }^{18}$; and an increase in total leukocytes, monocytes, neutrophils, eosinophils, and lymphocytes has been found in basketball players. ${ }^{16}$ Although lymphocytes present distinct responses (decrease, increase, or no alteration), total leukocytes and neutrophils seem to show a more similar pattern of increase towards a training season. ${ }^{16,17}$ The present study revealed an increase in total leukocyte, neutrophil, and monocyte counts, while lymphocytes decreased by the end of the season. The increase observed in lobulated neutrophils, segmented neutrophils, total neutrophils, and monocytes can be associated with muscle tissue remodelation, due to possible damage caused by training load and competition.

Furthermore, we can speculate that the higher training volume and intensity modulated the immune system, increasing the risk of immunosuppression and URI. ${ }^{10,14}$ The correlation between leukocyte number and higher incidence of URI shows the influence of a competitive period and 
Table 5 Pearson's correlations for leukocytes, cytokines, and training-load indicators

\begin{tabular}{|c|c|c|c|}
\hline Intervenient factors & MI & M2 & M3 \\
\hline Total leukocytes $\times \mathrm{TL}$ & & $0.73^{\mathrm{a}}$ & 0.17 \\
\hline Total leukocytes $\times$ MWL & - & -0.10 & 0.24 \\
\hline Total leukocytes $\times$ TWL & - & 0.44 & 0.31 \\
\hline Total leukocytes $\times$ SPTI & - & 0.51 & -0.21 \\
\hline Total leukocytes $\times$ SPTF & - & 0.57 & 0.35 \\
\hline Neutrophils $\times$ TL & - & 0.42 & 0.13 \\
\hline Neutrophils $\times$ MWL & - & 0.55 & 0.37 \\
\hline Neutrophils $\times$ TWL & - & $\left.0.7\right|^{\mathrm{a}}$ & 0.44 \\
\hline Neutrophils $\times$ SPTI & - & 0.51 & -0.10 \\
\hline Neutrophils $\times$ SPTF & - & $0.67^{\mathrm{a}}$ & 0.55 \\
\hline Lymphocytes $\times$ TL & - & -0.21 & -0.05 \\
\hline Lymphocytes $\times M W L$ & - & $-0.62^{\mathrm{a}}$ & -0.30 \\
\hline Lymphocytes $\times$ TWL & - & -0.55 & -0.33 \\
\hline Lymphocytes $\times$ SPTI & - & -0.31 & -0.38 \\
\hline Lymphocytes $\times$ SPTF & - & -0.46 & -0.24 \\
\hline $\mathrm{IL}-6 \times \mathrm{TL}$ & - & 0.49 & 0.24 \\
\hline $\mathrm{IL}-6 \times \mathrm{MWL}$ & - & 0.17 & 0.35 \\
\hline IL- $6 \times$ TWL & - & 0.46 & 0.45 \\
\hline IL-6 $\times$ SPTI & - & 0.24 & 0.20 \\
\hline IL-6 $\times$ SPTF & - & 0.41 & $0.7 I^{\mathrm{a}}$ \\
\hline TNF- $\alpha \times$ TL & - & 0.47 & 0.39 \\
\hline TNF- $\alpha \times$ MWL & - & 0.28 & 0.16 \\
\hline TNF- $\alpha \times$ TWL & - & 0.52 & 0.33 \\
\hline TNF- $\alpha \times$ SPTI & - & 0.30 & -0.49 \\
\hline TNF- $\alpha \times$ SPTF & - & 0.49 & -0.03 \\
\hline
\end{tabular}

Notes: Subjective perception of training intensity and volume (TL) in minutes, evaluated after court sessions (specific skills and physical capacities) and physical training (strength and jumping training). SPT evaluated initially (SPTI) and at the end (SPTF) of court sessions. Values are presented as mean \pm standard error of the

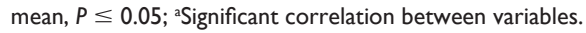

Abbreviations: IL, interleukin; MWL, mean weekly load; SPT, subjective perception of tiredness; TL, total load; TNF, tumor necrosis factor; TWL, total weekly load; MI, pre-competitive period; M2, competitive I period; M3, competitive II period.

training-load application, highlighting that the manipulation of training load can modulate the immune system. These modifications can be associated with the accumulated training load and competitions, as well as the individual immune response of each athlete in daily situations, such as psychology stress and food intake.

In contrast, Córdova et $\mathrm{al}^{1}$ demonstrated that during a 4-month volleyball season, immunoglobulin concentrations and lymphocyte count increased in elite men. These modifications can be interpreted as enhanced immunity. ${ }^{26}$ Interestingly, there was a positive correlation between all symptoms of upper respiratory tract infection and total weekly training load, SPTI, and SPTF. Thus, it can be speculated that both training-load parameters must be controlled to avoid training interruption due to illness.

Regarding cytokines, Masatoshi et a ${ }^{19}$ showed no significant change in IL-6 and TNF- $\alpha$ pro-inflammatory
Table 6 Pearson's correlations for URTI and training-load indicators

\begin{tabular}{|c|c|c|c|}
\hline Intervenient factors & MI & M2 & M3 \\
\hline Runny nose $\times$ TL & - & 0.37 & 0.41 \\
\hline Runny nose $\times M W L$ & - & 0.36 & 0.18 \\
\hline Runny nose $\times$ TWL & - & $0.60^{\mathrm{a}}$ & 0.37 \\
\hline Runny nose $\times$ SPTI & - & $0.63^{\mathrm{a}}$ & 0.54 \\
\hline Runny nose $\times$ SPTF & - & $0.79^{\mathrm{a}}$ & $0.74^{a}$ \\
\hline Cold $\times$ TL & - & 0.36 & -0.20 \\
\hline Cold $\times M W L$ & - & 0.18 & 0.20 \\
\hline Cold $\times$ TWL & - & $0.60^{\mathrm{a}}$ & 0.10 \\
\hline Cold $\times$ SPTI & - & $0.65^{\mathrm{a}}$ & $0.78^{\mathrm{a}}$ \\
\hline Cold $\times$ SPTF & - & $0.79^{a}$ & $0.85^{\mathrm{a}}$ \\
\hline Sore throat $\times T L$ & - & 0.48 & 0.48 \\
\hline Sore throat $\times M W L$ & - & 0.26 & 0.52 \\
\hline Sore throat $\times$ TWL & - & $0.74^{\mathrm{a}}$ & 0.40 \\
\hline Sore throat $\times$ SPTI & - & $0.67^{\mathrm{a}}$ & 0.51 \\
\hline Sore throat $\times$ SPTF & - & $0.74^{\mathrm{a}}$ & 0.56 \\
\hline Total symptoms $\times$ TL & - & 0.56 & 0.26 \\
\hline Total symptoms $\times \mathrm{MWL}$ & - & 0.27 & 0.46 \\
\hline Total symptoms $\times$ TWL & - & $0.78^{\mathrm{a}}$ & 0.36 \\
\hline Total symptoms $\times \mathrm{SPTI}$ & - & $0.80^{\mathrm{a}}$ & $0.72^{\mathrm{a}}$ \\
\hline Total symptoms $\times$ SPTF & - & $0.90^{\mathrm{a}}$ & $0.86^{\mathrm{a}}$ \\
\hline
\end{tabular}

Notes: Subjective perception of training intensity and volume (TL) in minutes, evaluated after court sessions (specific skills and physical capacities) and physical training (strength and jumping training). SPT evaluated initially (SPTI) and at the end (SPTF) of court sessions. Values are presented as mean \pm standard error of the

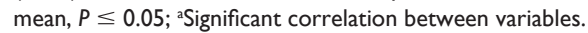

Abbreviations: IL, interleukin; MWL, mean weekly load; SPT, subjective perception of tiredness; TL, total load; TNF, tumor necrosis factor; TWL, total weekly load; MI, pre-competitive period; M2, competitive I period; M3, competitive II period; URTI, upper respiratory tract infection.

cytokines in female volleyball players during 1 month with increasing training load. In the present study, the same responses were found at the end of M2 and M3 when compared with the M1 training period. These findings are in contrast to the increases found in serum cytokines after endurance exercise, such as a marathon ${ }^{9,15,27}$ or prolonged treadmill tests. ${ }^{10,27}$

The discrepancy in IL- 6 and TNF- $\alpha$ in endurance athletes may be related with the time of blood draw, since runners were evaluated immediately after the race, ${ }^{9,10,15}$ characterizing an acute response. Furthermore, IL-6 exerts an important metabolic role by regulating fat and glucose metabolism during the continuum of exhaustive exercise.$^{28}$ Thus, possibly as a result of the intermittent nature of volleyball and other collective sports, cytokines exhibit a different pattern.

Considering that training load can be associated with environmental and psychological aspects, as well as the modulation induced by exercise, stress, and the neuroendocrine system, ${ }^{15,29}$ the increase in training load and competitions may be an important aspect that contributes to a decrease in the immune response. 
Furthermore, the hormone cortisol exerts an important action on leukocyte mobilization, specifically by increasing blood neutrophils. ${ }^{10}$ In this sense, cortisol and pro-inflammatory cytokines could promote the recruitment of cells from bone marrow.

There was an increase in innate immune cells (specifically monocytes and neutrophils), and a decrease in adaptive immune cells (total lymphocytes) and higher incidence of upper respiratory tract infections from the M1 to M2 training periods. These immune modulations can be associated with the proportional decrease of general exercises and an increase of special exercises, mainly competitive exercises, specific to the sport of volleyball. Moreover, the alterations in innate immunity, adaptive immunity, and the higher incidence of URI can be associated with an increase of the physical and tactical component during the M2 and M3 training periods.

Bury et al ${ }^{17}$ found a higher incidence of URI in football players than controls, with $77 \%$ of the cases taking place during winter. Similarly, there was an increase in URI symptoms in winter months, which were maintained at the end of spring, overlapping with the end of the season. URI symptoms in athletes may be related with seasonality and the accumulated effect of training loads. This observation is based in the positive correlations between neutrophils and training-load indicators at the end of the competitive I period (M2); and mainly by the positive correlations between URI symptoms and training-load indicators during all evaluations. Additionally, the increase in the percentage of competitive exercises and specific physical and tactical training components coincided with higher URI incidence.

Considering that monocytes, basophils, and eosinophils exhibited normal values as compared with reference values towards the evaluation periods, and that lymphocytes were above reference values in M1 and M2 but returned to normal values at the end of the season (M3), and cytokines were unchanged, from the immune point of view, there was an adaptation to training loads and competitions.

IL-2 synthesis by lymphocytes is considered to be an important determinant for protection against infections. ${ }^{10}$ Thus, the tendency of IL-2 to increase, associated with lymphocyte count, suggests a positive immune status to prevent URI symptoms. Despite the positive correlations between cell count and cytokines with URI at the end of the season, there was a longer period between M2 and M3. This issue can generate a misunderstanding of the immune status with the real mean URI symptoms in this period.
The present study was not designed to study the effect of diet consumption on the immune system during a training season. Therefore, diet consumption was not monitored, which can be considered a study limitation. Additionally, there was no control group and this limitation should be considered. Furthermore, more periodic evaluations, automated cell counting, and the measuring of cellfunction parameters (apoptosis and cytotoxicity) should be performed.

In summary, the present study suggests that immune variables, such as total leukocytes, neutrophils, and lymphocytes, can be modulated by training loads, mainly by tactical and physical components. Furthermore, a higher incidence of URI symptoms was correlated with immune cell count, demonstrating that training load and training components are important variables to be controlled. Thus, coaches should prevent negative immunological alterations associated with training load during in-season training and competition. However, there are few investigations relating to the immune system, training load, and seasonal training in volleyball players. Thus, the accumulated effect of sportspecific training loads on chronic immune modulations warrants further investigation.

\section{Acknowledgments}

The authors thank CAPES/PROSUP, FAP/UNIMEP, and PIBIC/CNPq for financial support; nurse Juliana Custódio de Oliveira for availability in blood collections; Patrícia Carla Paulino Belotto and Ana Elci da Silva Lima Pessotti for providing laboratory and technical support; the technical commission and athletes of the APIV volleyball team; and James Navalta, PhD, for performing the English revision.

\section{Disclosure}

The authors report no conflicts of interest in this work.

\section{References}

1. Córdova A, Sureda A, Tur JA, et al. Immune response to exercise in elite sportsmen during the competitive season. J Physiol Biochem. 2010;66(1):1-6.

2. Nieman DC. Marathon training and immune function. Sports Med. 2007;37(4-5):412-415.

3. Ortega E. Neuroendocrine mediators in the modulation of phagocytosis by exercise: physiological implications. Exerc Immunol Rev. 2003;9(1): 70-93.

4. Parry-Billings M, Budgett R, Koutedakis Y, et al. Plasma amino acid concentrations in the overtraining syndrome: possible effects on the immune system. Med Sci Sports Exerc. 1992;24(12): 353-1358.

5. Parry-Billings M, Leighton B, Dimitriadis GD, et al. Effects of physiological and pathological levels of glucocorticoids on skeletal muscle glutamine metabolism in the rat. Biochem Pharmacol. 1990;40(5): 1145-1148. 
6. Anderson L, Triplett-Mcbride T, Foster C, et al. Impact of training patterns on incidence of illness and injury during a women's collegiate basketball season. J Strength Cond Res. 2003;17(4):734-738.

7. Jonsdottir IH. Exercise immunology: neuroendocrine regulation of NK-cells. Int J Sports Med. 2000;21(1):S20-S23.

8. Mackinnon LT. Effects of exercise on the immune system: overtraining effects on immunity and performance in athletes. Immunol Cell Biol. 2000;78(5):502-509.

9. Nieman DC. Immune response to heavy exertion. J Appl Physiol. 1997; 82(5):1385-1394.

10. Pedersen BK, Hoffman-Goetz L. Exercise and the immune system: regulation, integration, and adaptation. Physiol Rev. 2000;80(3): 1055-1081.

11. Steensberg A, Toft AD, Bruunsgaard H, et al. Strenuous exercise decreases the percentage of type $1 \mathrm{~T}$ cells in the circulation. $J$ Appl Physiol. 2001;91(4):1708-1712.

12. Nieman DC, Johanssen LM, Lee JW, et al. Infections episodes in runners before and after the Los Angeles Marathon. J Sports Med Phys Fitness. 1990;30(3):321-328.

13. Peters EM, Bateman ED. Ultramarathon running and upper respiratory tract infections. S Afr Med J. 1983;64(15):582-584.

14. Gleeson M. Immune function in sport and exercise. J Applied Physiol. 2007;103(2):693-699.

15. Pedersen BK, Toft AD. Effects of exercise on lymphocytes and cytokines. Br J Sports Med. 2000;34(4):246-251.

16. Benoni G, Bellavite P, Adami A, et al. Changes in several neutrophil functions in basketball players before, during and after the sports season. Int J Sports Med. 1995;16(1):34-37.

17. Bury T, Marechal R, Mahieu P, et al. Immunological status of competitive football players during the training season. Int J Sports Med. 1998; 19(5):364-368.
18. Rebelo AN, Candeias JR, Fraga MM, et al. The impact of soccer training on the immune system. J Sports Med Phys Fitness. 1998;38(3): 258-261.

19. Masatoshi S, Kawai T, Kimura H, et al. Natural killer cell lytic activity and CD56dim and CD56bright cell distributions during and after intensive training. J Appl Physiol. 2004;96(6):2167-2173.

20. Turnbull AV, Rivier CL. Regulation of the hypothalamic-pituitaryadrenal axis by cytokines: actions and mechanisms of action. Physiol Rev. 1999;79(1):1-71.

21. Jackson AS, Pollock ML, Ward A. Generalized equations for predicting body density of women. Med Sci Sports Exerc. 1980;12(3): 175-182.

22. Foster $\mathrm{C}$. Monitoring training in athletes with reference to overtraining syndrome. Med Sci Sports Exerc. 1998;30(7):1164-1168.

23. Borg G. Borg's Perceived Exertion and Pain Scales. Champaign, IL: Human Kinetics; 1998.

24. Tsai ML, Chou KM, Chang CK, Fang SH. Changes of mucosal immunity and antioxidation activity in elite male Taiwanese taekwondo athletes associated with intensive training and rapid weight loss. $\mathrm{Br} J$ Sports Med. 2011;45(9):729-734.

25. Pedersen B, Bruunsgaard H. How physical exercise influences the establishment of infection. Sports Med. 1995;19(6):393-400.

26. Mackinnon LT. Immunoglobulin, antibody, and exercise. Exerc Immunol Rev. 1996;2(1):1-35.

27. Pedersen BK, Fischer CP. Beneficial health effects of exercise - the role of IL-6 as a myokine. Trends Pharmacol Sci. 2007;28(4):152-156.

28. Prestes J, Ferreira CKO, Dias R, et al. Lymphocyte and cytokines after short periods of exercise. Int J Sports Med. 2008;29(12):1-5.

29. Smith DJ, Roberts D, Watson B. Physical, physiological and performance differences between Canadian national team and universiade volleyball players. J Sports Sci. 1992;10(2):131-138.
International Journal of General Medicine

\section{Publish your work in this journal}

The International Journal of General Medicine is an international, peer-reviewed open-access journal that focuses on general and internal medicine, pathogenesis, epidemiology, diagnosis, monitoring and treatment protocols. The journal is characterized by the rapid reporting of reviews, original research and clinical studies across all disease areas.

\section{Dovepress}

A key focus is the elucidation of disease processes and management protocols resulting in improved outcomes for the patient. The manuscript management system is completely online and includes a very quick and fair peer-review system. Visit http://www.dovepress.com/ testimonials.php to read real quotes from published authors. 